\title{
The Value Cocreation Influence Mechanism of Network Freight Transport Platform in IoT-Based Environments: Under the Service-Dominant Logic
}

\author{
Pengxia Bai $\mathbb{D}^{1,2}$ Qunqi Wu, ${ }^{2,3}$ Qian Li ${ }^{3},{ }^{3}$ Lei Zhang, ${ }^{4}$ Yahong Jiang, ${ }^{1,2}$ and Bo Chen ${ }^{1,2}$ \\ ${ }^{1}$ School of Transportation Engineering, Chang'an University, Xi'an 710064, China \\ ${ }^{2}$ Integrated Freight Transportation Economics and Management Research Center, Chang'an University, Xi'an 710064, China \\ ${ }^{3}$ School of Economics and Management, Chang'an University, Xi'an 710064, China \\ ${ }^{4}$ Massey Business School, Massey University, Palmerston North 4442, New Zealand
}

Correspondence should be addressed to Qian Li; q.li@chd.edu.cn

Received 12 April 2021; Revised 3 May 2021; Accepted 6 May 2021; Published 24 May 2021

Academic Editor: Wei Wang

Copyright (c) 2021 Pengxia Bai et al. This is an open access article distributed under the Creative Commons Attribution License, which permits unrestricted use, distribution, and reproduction in any medium, provided the original work is properly cited.

The Internet of Things (IoT) has brought many benefits to the development of industries, from manufacturing to services. In the context of IoT, the network freight transport platform is equivalent to an integrator, integrating the scattered resources such as carriers and shippers in the supply chain, providing a solution, improving the use efficiency of vehicles, effectively reducing logistics cost, and creating value for the freight transport platform and bilateral customers. The purpose of this research is to explain the influence mechanism of transport demand subjects' participation in value cocreation (VCC) under the servicedominant logic (SDL). We proposed a conceptual framework and 10 hypotheses and used SEM to measure the direct and mediating relationship among SDL, transport demand subject (TDS) participation, relational embeddedness (RE), platform VCC, and TDS value in the online business environment. The findings show that (1) SDL, TDS participation, and RE do not directly affect the TDS value, but indirectly through platform VCC; (2) SDL affects platform VCC not only directly but also indirectly through TDS participation and RE; (3) TDS participation affects platform VCC not only directly but also indirectly through RE; (4) RE indirectly affects TDS value by affecting platform VCC; and (5) platform VCC plays a mediating role in SDL, TDS participation, RE, and TDS value. Hence, transport enterprises should pay attention to the innovation concept, guide TDS participation, jointly improve platform VCC, give play to the network effect of the freight transport platform, and achieve TDS value through the deepening of TDS relationship embedding.

\section{Introduction}

The rapid growth of the Internet of Things (IoT) causes a sharp growth of data [1]. Enormous amounts of networking sensors are continuously collecting and transmitting data to be stored and processed in the cloud [2]. Such data can be environmental data, geographical data, astronomical data, logistic data, and so on. Mobile devices, transportation facilities, public facilities, and home appliances are the primary data acquisition equipment in IoT. It is a trend to use information technology and the Internet to transform the traditional transport industry. Network freight transport is developed on the basis of the vehicle and cargo matching platform developed by using the Internet technology [3]. Through the Internet platform and digital technology reference, with the intervention of big data, the whole network freight transport is interconnected and interoperated and the industry is upgraded with the help of the smart logistics model. In addition, the Ministry of Transport proposed to use the "Internet" to develop efficient logistics. Therefore, through the development of network freight, freight operators can effectively solve the tax burden, freight settlement, and insurance concerns in the field of distribution and tally. Network freight transport can not only help enterprises to achieve efficient allocation of transport capacity resources but also help logistics enterprises to truly achieve cost reduction and efficiency increase [4]. 
Although the emergence of a network freight transport platform has solved many problems for China's transport industry, there are still many problems. For example, high investment cost, poor connection of logistics links, and low efficiency lead to low performance of the whole logistics service supply chain. Therefore, this paper explores the way to improve the performance of the logistics service supply chain from the perspective of the customers. It must be emphasized that the customers in this paper refer to manufacturing enterprises. Under the demand-oriented logic, transport services become more and more important. In order to increase customer value, customer engagement is very important. Driven by the Internet, the emergence of a freight transport platform has brought great benefits to the output of the customer value. Therefore, how to increase the value output of customers is the main problem of this paper. From the perspective of customer demand, this paper explains the influence mechanism among service-dominant logic, customer participation, relational embeddedness, value cocreation, and customer value.

The rest of the article is organized as follows. Section 2 is about the theoretical basis and research hypothesis. Section 3 is about the research method. The research adopted a questionnaire survey approach, including questionnaire design, data collection, reliability, and validity test. In Section 4, results analysis, hypothesis verification, and model interpretation are presented. The last section contains the research conclusions and management implications.

\section{Theoretical Basis and Research Hypothesis}

\subsection{Theoretical Basis}

2.1.1. Service-Dominant Logic (SDL). Service-dominant logic $(\mathrm{SDL})$ replaces the traditional product-dominant logic. Based on SDL, reexamine the relationship between services and products and then think about the core issues in economic exchange and value creation [5]. SDL is a service-centered alternative to the traditional goods-centered paradigm. This service-centered view suggests that market exchange is a process in which the parties utilize their expertise for the benefit of each other, i.e., mutual provision of services [6]. Since Vargo and Lusch proposed it in 2004, SDL has been revised three times in 2006, 2008, and 2016 and has developed from the original 8 basic propositions to 11.The main content includes the following: the application of operational resources (knowledge and skills) is the foundation of all exchanges. Thus, all economies are service economies. SDL establishes the priority of operational resources over objective resources. Operational resources refer to the resources that generate revenue through the operation of other resources, such as knowledge, skills, and capabilities. Objectivity resources refer to the resources that must be used to generate benefits, such as natural resources, commodities, and money. That is, operational resources such as knowledge and skills are potential sources of value. In addition, SDL believes that the resources for creating value are not limited to the company; customers, suppliers, and other stakeholders also constitute operational resources and contribute to the creation of value [7]. Value is always created with the customer and others, so the business cannot create and deliver value alone. They can only make value propositions and provide services as inputs to realize the value. Ultimately, value is determined contextually by the service beneficiary (i.e., the customer). Vargo and Lusch further improved the theory of SDL and believed that value cocreation is coordinated through institutions and institutional arrangements created by participants.

2.1.2. Customer Participation (CP). Customer participation (CP) refers to the input provided by the customer, including effort, time, knowledge, or other resources [8-11]. However, some scholars believe that CP is "the act of customers investing various resources to create value with suppliers " $[4,12]$. In essence, the basic exchange unit is service rather than product. In this way, suppliers can cocreate value by exchanging services with customers [13]. They actively create value with suppliers to better meet their individual needs and improve their satisfaction [14]. With the change of customer demand and the progress of technology, the role of customers and enterprises in value creation has changed [15]. On the one hand, compared with the past, customers are more willing and able to participate in the development of the company's products and services $[13,16]$. For customers, being actively involved in value cocreation makes them more satisfied than those who are not, encourages them to be more innovative, and increases their motivation and willingness to take risks [17]. On the other hand, enterprises have gradually realized that only by guiding the active participation of customers can they timely understand the needs of customers and better realize the "customization" of customer needs $[3,18]$. Due to the influence of customer satisfaction and loyalty, customer participation in value cocreation is crucial to help enterprises gain competitive advantages.

2.1.3. Relational Embeddedness (RE). Relational embeddedness (RE) is a core concept in the research of new economic sociology and an important tool for the study of a corporate relationship network [9]. It has a certain impact on enterprises' resource acquisition, knowledge sharing, technological innovation, and other behaviors and further affects the improvement of corporate performance and the shaping of competitive advantages $[18,19]$. This paper proposes that $\mathrm{RE}$ refers to the degree to which transport demand subjects participate in value cocreation. In the context of freight logistics service, with the changes in the competitive environment and differentiated needs of customers, small- and medium-sized freight logistics firms continue to carry out alliance innovation. Due to the lack of relevant theoretical research, it is difficult to support the management and sustainable development of freight logistics firms. The purpose is to promote mutual learning between value cocreation subjects to create value and reduce transaction costs at the same time, so as to make the network platform produce the best profit [20]. This study focuses on Manbang company, which is a professional organization whose primary value creation activities include the accumulation, creation, and dissemination of knowledge to provide 
customized services or solutions that meet the need of transport demand subjects.

2.1.4. Value Cocreation (VCC). Value is cocreated in the customer experience at different points of interaction, where products, distribution channels, technology, and people are seen as gateways to the experience $[9,21]$. Therefore, customers are active partners in the process of shared value creation, rather than simply passive acceptance of the value created by others. Value cocreation (VCC), as a general concept describing the collaboration between multiple stakeholders, has attracted the attention of scholars and practitioners $[1,22]$. On the one hand, enterprises should open research and development, production, marketing, sales, and other value links to meet the needs of customers and carry out more adequate communication and interaction with customers [23]. On the other hand, customers (demanders) can apply their own knowledge, skills, and experience to value creation activities, such as putting forward demands, purchasing, and using products or services, so as to achieve rapid demand satisfaction and better experience [2]. Suppliers and demanders are involved in each other's value creation, so as to realize the integration and collaboration of both sides in resources, capabilities, and knowledge, so as to better meet customer needs and improve enterprise performance $[16,19]$. The main activity involved in platform value cocreation is resource integration [24, 25]. According to the view of SDL, both suppliers and demanders can act as resource integrators [26]. In addition, other social and economic actors can also act as resource integrators. Customer participation is the microbasis of value cocreation, resource integration and participation platforms play a central role in value cocreation, and service ecology and business models are the macroexpression of value cocreation [27]. Therefore, this paper proposes that value cocreation refers to the multiparties such as customers, suppliers, and platform providers to create network effects through mutual cooperation and resource sharing through the network platform and jointly realize value creation.

\subsection{Research Hypothesis and Theoretical Framework}

2.2.1. SDL and Transport Demand Subject Value (TDS Value). VCC is an important issue in the study of SDL. Many propositions in SDL are descriptions of VCC. For example, service (the use of operational resources such as knowledge and skills) is the fundamental basis of exchange [28]. Value is created by the cocreation of multiple participants [12]. One of the most prominent views of cocreation is the SDL, which emphasizes the concept of coproducing value and the need to cocreate value. In essence, the basic unit of exchange is a service rather than a product, so that vendors can cocreate value by exchanging services with customers [16]. SDL also states that value is created through institutions created by resource integrators (all economic and social actors) and cocreated under institutional arrangements [17, 23]. Under the guidance of the SDL concept, platform enterprises more clearly realize that it is difficult to achieve value creation only by relying on their own ability and it requires the joint participation of customers, channel partners, employees, suppliers, and other stakeholders [3]. Through distributors or staff for the feedback of the customer requirements and delivery, the enterprise through the network platform integrates the resources of the upstream suppliers and develops and provides products and services, through the downstream distributors, to meet the needs of the customer; at the same time, the enterprise and stakeholders to achieve the win-win situation do common realization of value creation [29]. Therefore, the following hypothesis is proposed: H1-SDL has a significant positive effect on TDS value.

\subsubsection{SDL and Transport Demand Subject Participation (TDS}

Participation). According to the SDL, value is by nature collaborative and cocreated rather than created by a single actor. As a result, customers are seen as valuable creators, as opposed to passive responders or receivers. The customers are active participants in the relationship communication, and they work with the organization to cocreate value through the entire service value chain [18]. In this role, the customers may go beyond the activities and responsibilities that traditionally belong to the sales organization, such as self-service or generating ideas for service improvement [30]. In this case, they are always involved in the VCC and play a key role in defining the relevant interests of each product or service solution [31]. TDS participation can play a variety of roles to help themselves, others, and the supplier [20]. Customers use their own skills to integrate resources and create value [32]. SDL shows that suppliers and demanders always work together to create value [33]. Therefore, the following hypothesis is proposed: $\mathrm{H} 2-\mathrm{SDL}$ has a significant positive effect on TDS participant.

2.2.3. SDL and RE. SDL holds that all economies are service economies and all participants of economic activities and social activities are resource integrators [34]. Since service economy involves many subjects and organizations, each subject integrates resources in economic activities in order to achieve its own goals [35]. It has become one of the indispensable resources for enterprises to participate in the process of market competition that they have good social relations or occupy favorable social network position (such as network centrality) [5]. Because of the strong resource allocation effect of the social network, enterprises can obtain more scarce resources at a lower cost and faster speed [21]. Therefore, the social network has become an important way for enterprises to obtain resources [36]. According to SDL, "the view of service center must be customer-oriented and relational." "Customer orientation" emphasizes the core position of customers in the service economy, and "relationship" emphasizes the relationship among customers, enterprises, and VCC subjects. The relationship between the enterprise and network members is the cornerstone of analyzing and exploring the influence of network embeddedness on enterprise behavior [22]. Therefore, the following hypothesis is proposed: H3-SDL has a significant positive effect on RE.

2.2.4. SDL and VCC. SDL defines service as "the ability to apply for the benefit of others," which is regarded as the 
theoretical basis for the development of service science and the research of the service system [8]. The main body of VCC uses the service system to provide resource sharing, including information sharing, work sharing, risk sharing, and commodity sharing [37], and realizes the connection and interaction between the parties through the ability of the service system (such as knowledge, skills, and technology) [38]. Under the common value proposition, VCC is realized through resource complementarity and ability integration [39]. In the new service system, the purpose and driving force of interaction and exchange is value creation [40]. The service ecosystem is an ecosystem approach based on SDL, which focuses on service exchange and resource integration [41]. The service ecosystem is considered to be the research direction of SDL in the next 10 years. VCC in the service ecosystem means that a wide range of social and economic participants (including customers, suppliers, and distributors) creates value for themselves and other systems through service exchange and resource integration in the ecosystem [42]. First of all, SDL holds that an institution is an important factor to realize VCC [43]. Institutions promote cooperation and coordination of activities in ecosystems by providing a shared code of conduct [44]. The system in this paper refers to the win-win business model and value chain integration mechanism of the service ecosystem. Second, SDL focuses on dynamic resources (such as knowledge and skills), which are important resources to enhance the core competence of an enterprise. Through the network platform, the enterprise aggregates the knowledge and skills accumulated by various subjects and forms the core competence, which has the characteristics of value, uniqueness, and irreplaceability [2]. Finally, VCC under the service ecosystem needs the network platform as the intermediary and the VCC subject realizes value creation through the network platform. VCC in this paper contains three dimensions, namely, information sharing (IS), responsible behavior (RB), and the interaction between the supplier and demander (ISD). The network platform needs to use new technologies, improve the platform capacity, absorb and integrate multiple heterogeneous resources, meet the needs of multiple subjects of resource integration and service exchange, and finally achieve VCC. Therefore, the following hypotheses are proposed: $\mathrm{H} 4-\mathrm{SDL}$ has a significant positive impact on VCC. H4a-SDL has a significant positive impact on IS. H4b-SDL has a significant positive impact on $\mathrm{RB}$. $\mathrm{H} 4 \mathrm{c}-\mathrm{SDL}$ has a significant positive impact on ISD.

2.2.5. TDS Participation and VCC. The VCC process assumes that all participants are willing and ready to share complementary expertise and skills in order to create a win-win situation for each of the actors involved [45]. In this context, TDS is seen as a key resource in the value creation process. TDS participation needs to jointly develop the value proposition, which is the result of the negotiation between the parties. Suppliers' ability to engage in positive dialogue and interaction with demanders increases their potential to support value creation, and suppliers also use their expertise to provide products and services to demanders. In addition to paying money, demanders must sacrifice time and effort to obtain products and services; demanders also contribute resources such as knowledge in the use of products and services to create the best use value [10]. Therefore, TDS needs to achieve the best balance between the benefits of use value and the cost of effort. There are three forms of customer participation: one is customer communication (that is, customer-to-customer communication), which refers to word of mouth (positive and negative), and helping others [8]. The second is customer complaint, which refers to the interactive behavior of customers giving feedback, information communication, and seeking solutions to the company in the process of using the product or service [4]. The third is customer collaboration, such as customer participation in product development and innovation [11]. Research shows that VCC benefits both suppliers and demanders. Therefore, the following hypothesis is proposed: H5-TDS participation has a significant positive effect on platform VCC.

2.2.6. TDS Participation and RE. TDS participation refers to the behavior that TDS invests all kinds of resources to create value with the suppliers [19]. The resources invested by TDS include their efforts and investment in time, spirit, intelligence, entity, and emotion. Whether TDS participate in product development or service delivery or the communication and interaction between customers, they all need to solve problems together through information sharing on the basis of mutual trust. TDS participation can increase the level of network embeddedness [15]. RE reflects the relationship characteristics between suppliers and demanders, such as relationship quality [46]. Granovetter measures RE using interaction frequency, intimacy, relationship duration, and mutual service content. RE can increase the mutual recognition and trust between suppliers and demanders, as well as between demanders, and enhance the interaction and sharing between them [17]. Therefore, the following hypothesis is proposed: H6-TDS participation has a significant positive effect on RE.

2.2.7. TDS Participation and VCC. Companies can benefit from customer innovation by creating dedicated platforms to promote customer creativity. The network platform has the characteristics of interactivity, continuity, rapidity, and flexibility, which can be used by enterprises to attract customers to actively participate in VCC [47]. On the one hand, in order to realize customer participation in enterprise VCC, enterprises need to develop a special platform to support the exchange and interaction between suppliers and demanders and demanders and demanders. On the other hand, in order to meet the needs of customer, suppliers not only need to mobilize internal forces but also need to integrate the forces and resources of distributors and demanders. This requires the platform to have a fast, flexible, value chain integration mechanism, with the core ability to quickly respond to customer needs; at the same time, the platform also has strong technological innovation ability. Therefore, TDS participation can enhance platform capabilities, including value chain integration capabilities, organizational core capabilities, and technology research and development capabilities. Accordingly, the following hypotheses are proposed: H7-TDS 


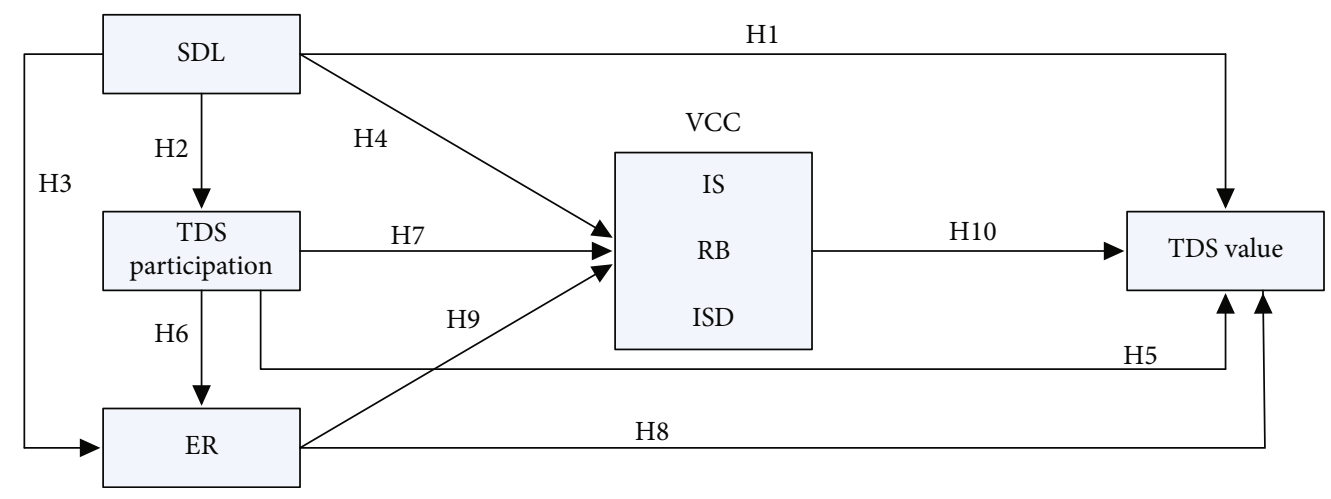

FIgure 1: The theoretical model.

participation has a significant positive impact on VCC. H7a-TDS participation has a significant positive impact on IS. H7b-TDS participation has a significant positive impact on RB. H7c-TDS participation has a significant positive impact on ISD.

2.2.8. RE and TDS Value. This paper proposes that TDS participation has influence on VCC from the aspects of cognitive embedding, structural embedding, and RE. First of all, cognitive embedding is beneficial for the VCC subjects to reach a consensus and contribute to the generation of VCC behaviors of each subject. Secondly, structure embedding is conducive to platform enterprises to obtain more heterogeneous information and resources more efficiently and promote platform enterprises to realize value creation through the integration and utilization of internal and external resources. Structural embedding is to embed economic relations into the structure of the social relations network. The larger the network scale, the more partners the platform enterprises connect, and the richer the network resources. Third, RE is beneficial to the establishment of cooperation and trust among VCC subjects and to the acquisition of knowledge, technology, and other resources necessary for VCC from the relationship network [48]. In short, RE can absorb more heterogeneous resources such as knowledge, information, and technology and promote VCC. Therefore, the following hypothesis is proposed: $\mathrm{H} 8-\mathrm{RE}$ has a significant positive effect on TDS value.

2.2.9. RE and VCC. Different structural characteristics of embedded networks have different effects on the acquisition, integration, and reconstruction of resources [49]. Some scholars found that enterprises can improve the dynamic capability of the organization through RE, so as to grow in the turbulent environment. First of all, RE is conducive to the establishment of cooperation between enterprises, helps to build a business model with platform providers as the core, and promotes the improvement of value chain integration ability. Secondly, RE is beneficial to the improvement of the core competence of the organization. Through the learning and integration of external knowledge, RE can improve the organizational flexibility and core dynamic capabilities of enterprises, such as timely understanding of external envi- ronment changes and timely response to customer needs. Third, RE can promote the improvement of enterprises' technological innovation ability. RE helps platform enterprises to develop and provide new products and services by integrating multiple resources. In this process, knowledge should be transformed into capabilities through technology and productivity should be formed to realize value creation. Therefore, the following hypotheses are proposed: H9-RE has a significant positive impact on VCC. H9a-RE has a significant positive impact on IS. H9b-RE has a significant positive impact on $\mathrm{RB}$. $\mathrm{H} 9 \mathrm{c}-\mathrm{RE}$ has a significant positive impact on ISD.

2.2.10. VCC and TDS Value. Platform plays an intermediary role in VCC, and VCC has a significant impact on TDS value [50]. First, IS has a significant impact on TDS value. IS means to share a win-win benefit distribution mechanism among VCC subjects, integrate the resources of upstream and downstream partners of the value chain, and form a synergistic and complementary ability with platform providers. Secondly, $\mathrm{RB}$ has a significant impact on TDS value. RB includes data sharing such as product development, market operations, and customer service, as well as human, financial, and technical management data. RB is formed by enterprises for a long time [51]. It has the characteristics of heterogeneity, value, difference, and irreplaceability and can bring unique value to customers. Therefore, $\mathrm{RB}$ can promote the creation of demander value. Finally, ISD has a significant impact on TDS value. ISD is an important link of the platform. On the one hand, to realize the interaction between demanders and suppliers, it is necessary to provide a platform and tools for VCC to realize value creation among all parties. On the other hand, platforms need to be capable of creating new products and services through continuous technological iteration. Therefore, this paper puts forward the following hypotheses: H10-VCC has a significant positive impact on TDS value. $\mathrm{H} 10 \mathrm{a}-\mathrm{IS}$ has a significant positive impact on TDS value. $\mathrm{H} 10 \mathrm{~b}-\mathrm{RB}$ has a significant positive influence on TDS value. $\mathrm{H} 10 \mathrm{c}$-IDS has a significant positive influence on TDS value.

According to theoretical analysis, a theoretical framework is constructed to explain the influence mechanism among SDL, TDS participation, RE, VCC, and TDS value (see Figure 1). 
TABLE 1: Reliability and validity.

\begin{tabular}{|c|c|c|c|c|c|c|c|}
\hline Latent variable & Dimension & $\begin{array}{l}\text { Average } \\
\text { value }\end{array}$ & $\begin{array}{l}\text { Standard } \\
\text { deviation }\end{array}$ & $\begin{array}{l}\text { Factor } \\
\text { loading }\end{array}$ & $\begin{array}{l}\text { Cumulative variance contribution rate } \\
\qquad(\%)\end{array}$ & KMO & $\begin{array}{c}\text { Cronbach's } \\
\alpha\end{array}$ \\
\hline SDL & & 6.76 & 0.58 & 0.73 & 74.58 & 0.86 & 0.92 \\
\hline \multirow{5}{*}{$\begin{array}{l}\text { TDS } \\
\text { participation }\end{array}$} & TDSP1 & 6.74 & 0.51 & 0.81 & 78.32 & 0.87 & 0.91 \\
\hline & TDSP2 & 6.78 & 0.52 & 0.84 & 69.99 & 0.84 & 0.91 \\
\hline & TDSP3 & 6.71 & 0.51 & 0.78 & 83.12 & 0.82 & 0.93 \\
\hline & TDSP4 & 6.73 & 0.53 & 0.79 & 81.39 & 0.84 & 0.94 \\
\hline & TDSP5 & 6.77 & 0.53 & 0.76 & 79.85 & 0.83 & 0.89 \\
\hline \multirow{3}{*}{$\mathrm{RE}$} & RE1 & 6.78 & 0.54 & 0.81 & 81.45 & 0.87 & 0.88 \\
\hline & RE2 & 6.72 & 0.55 & 0.83 & 84.42 & 0.91 & 0.91 \\
\hline & RE3 & 6.71 & 0.57 & 0.82 & 78.65 & 0.89 & 0.93 \\
\hline \multirow{3}{*}{ VCC } & IS & 6.74 & 0.54 & 0.79 & 82.67 & 0.74 & 0.94 \\
\hline & $\mathrm{RB}$ & 6.69 & 0.56 & 0.71 & 81.34 & 0.79 & 0.91 \\
\hline & ISD & 6.75 & 0.51 & 0.84 & 76.45 & 0.82 & 0.95 \\
\hline TDS value & & 6.74 & 0.56 & 0.81 & 73.28 & 0.76 & 0.89 \\
\hline
\end{tabular}

\section{Research Design}

3.1. Sample Selection and Data Collection. This study takes the Manbang Group as a freight transport platform provider to conduct an investigation. In this study, the Manbang Group as a freight transport platform provider was taken as an example to conduct an investigation. The respondents were manufacturing enterprises, and the samples were from 21 provinces (municipalities) in Mainland China. The survey lasted from January 2021 to March 2021, and a total of 857 questionnaires were collected, and 786 valid questionnaires were collected after the unqualified questionnaires were eliminated. As a whole, the survey subjects are widely distributed and all of them have experience in the use of a Manbang freight transport platform. The validity of the data is guaranteed and the basic requirements of the research are met.

3.2. Questionnaire Design and Measurement Scale. On the basis of referring to the previous research scale, the authors designed the scale items combined with the actual. As most of these variables are difficult to be measured objectively and quantitatively, this study adopts the Likert seven-grade scale scoring method to measure them. A numerical scale of 1 to 7 indicates disagreement to agreement or a transformation from low to high. 4 represents the intermediate state [52]. Through soliciting opinions from sampling transport demand enterprises, consulting experts in the transport industry, and small-scale pretesting, the initial questionnaire was improved and the final survey questionnaire was formed on this basis.

3.3. Homologous Deviation and Integration Test. The questionnaire survey is conducted online, so homology deviation test should be carried out on the latent variable data, and four common factors with characteristic roots greater than 1 should be extracted. The explanatory variance of the first common factor is $32.9 \%$, and the cumulative explanatory variance is $71.37 \%$, which does not exceed the standard of
$40 \%$, so it can be used for data analysis. All the variables involved are the investigation of the phenomenon at the overall level of the organization. According to the suggestions of Shen et al. [27], the James formula is adopted to calculate the internal consistency coefficient RWG for testing and RWG $(0.71 \sim 0.78)$ is greater than 0.70 , indicating that it is feasible to integrate individual measurement data into data at the organizational level [52].

\section{Research Results}

4.1. Reliability and Validity. After the research team received the completed questionnaires, reliability analysis and validity analysis are generally two initial analyses that must be conducted to verify. The software SPSS 25.0 is used to analyze reliability and validity. For reliability, it is crucial to produce stable and consistent results. The higher the test reliability is, the more reliable the result is. There are many ways to measure the reliability. Cronbach's coefficient alpha is widely used in almost all questionnaire reliability analyses. Generally speaking, the alpha coefficient should be above 0.8 and $0.7 \sim 0.8$ is an acceptable range. Nevertheless, the alpha coefficient of the subscale should be above 0.7 and $0.6 \sim 0.7$ is acceptable. If the reliability coefficient is lower than 0.6 , the scale should be modified [52]. In this study, the Cronbach's coefficients are all greater than 0.7 and are within the acceptable range (see Table 1). Therefore, it indicates that the reliability of the questionnaire is qualified [52].

Validity is the degree to which the measured results reflect the content to be examined. The validity of the questionnaire could be checked by the constructs of criterion validity and coherency. Bartlett test of sphericity and KMO (Kaiser Meyer-Olykin measure of sampling adequacy) are used to analyze the structure validity in this paper. Results of KMO are all greater than 0.71 (see Table 1), and the Bartlett statistic is different from 0 [52]. Therefore, the validity of the questionnaire is excellent. 


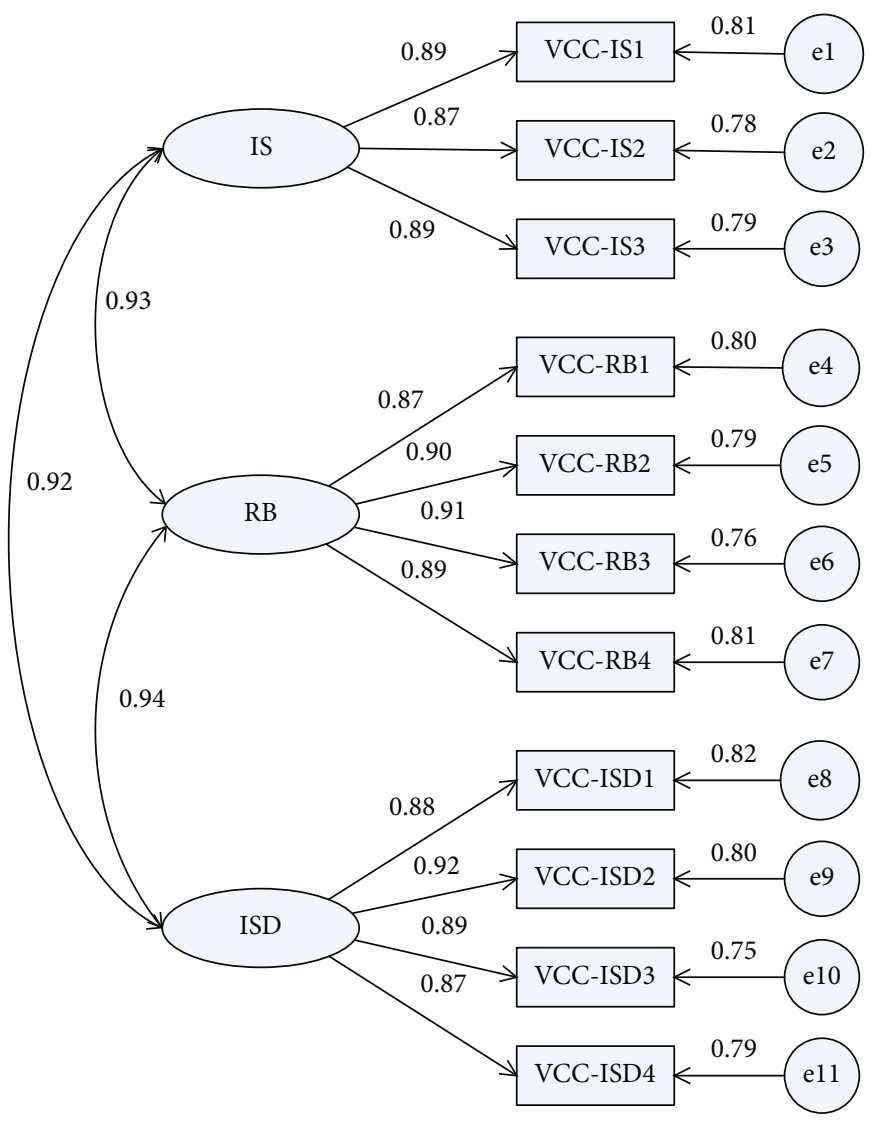

Figure 2: VCC first-order factor model.

4.2. CFA Test. By using software AMOS22 to conduct confirmatory factor analysis, it is found that the factor loading values of IS, RB, and ISD in value cocreation are within the range of $0.91 \sim 0.94$ (see Figure 2), indicating that there is a correlation among the three potential variables and the correlation is relatively high (greater than 0.5). Second-order confirmatory factor analysis can be continued.

The second-order CFA test was performed on IS, RB, and ISD. Figure 3 shows that the three strongly correlated first-order factors (IS, RB, and ISD) are generally affected by a high-order factor (VCC) and the factor load coefficient is in the range of $0.95 \sim 0.98$ (greater than 0.7 ). It is shown that the second-order latent variable VCC can represent three first-order latent variables, namely, IS, RB, and ISD.

\subsection{SEM Test}

4.3.1. Structural Equation Analysis of the Integrated Model. AMOS22 was used to construct the structural equation model, modify the MI index of the model, and analyze the model. The fitting indexes and their values of the integrated model were shown in Table 2, and the fitting indexes all met the requirements.

The path coefficient and hypothesis test in the structural equation of the integrated model are shown in Table 3.

The following conclusions can be drawn from Table 3:
(1) SDL, TDS participation, and RE do not directly affect TDS value but indirectly through platform VCC

(2) SDL indirectly influences VCC through RE and then realizes TDS value through VCC. Under the guidance of the SDL concept, transport enterprises, manufacturing enterprises, and other value-creating entities realize resource integration with the support of VCC through RE and finally realize TDS value

(3) SDL indirectly significantly affects TDS value through TDS participation and through VCC

(4) TDS participation significantly affected RE. The path coefficients all reach the significant level, indicating that the demand of TDS can directly affect the transportation service providers and promote the transportation enterprises to update the transportation service, instead of the traditional model from product to customer

(5) RE significantly affected VCC, and RE significantly affected TDS value through VCC

Therefore, it is assumed that H2, H3, H4, H6, H7, H9, and $\mathrm{H} 10$ are all supported. Moreover, from the perspective of TDS value, value cocreation plays an important intermediary role in TDS participation in service innovation of a freight transport platform. 


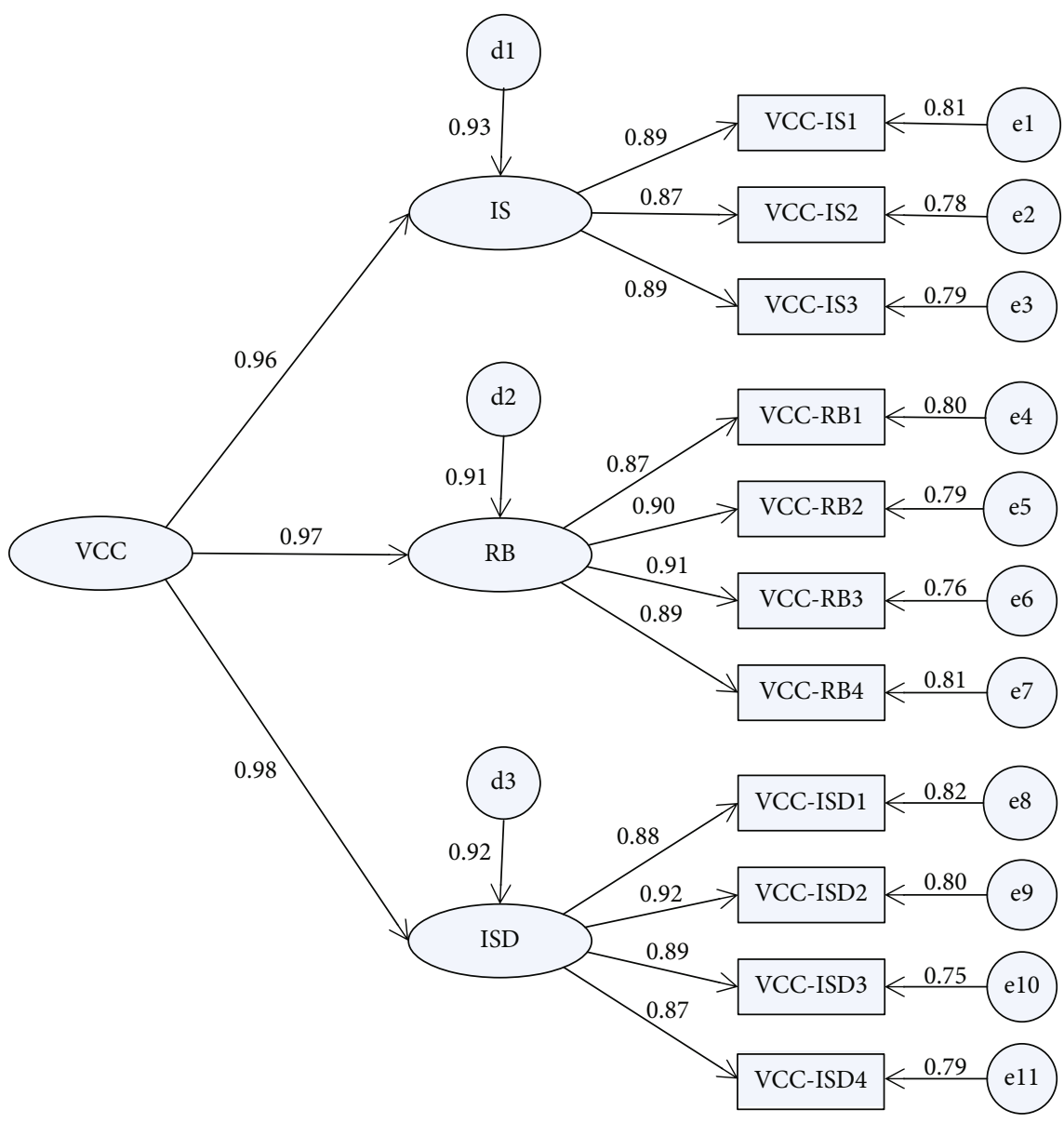

FIgURE 3: VCC second-order factor model.

TABLE 2: Fitting results of the integrated model.

\begin{tabular}{lcccccccc}
\hline Items & $\chi^{2} / d f$ & RMSEA & IFI & CFI & TLI & PGFI & PNFI & PCFI \\
\hline Index value & 4.684 & 0.065 & 0.932 & 0.927 & 0.918 & 0.784 & 0.854 & 0.863 \\
Measuring standard & $<5$ (large sample) & $<0.08$ & $>0.9$ & $>0.9$ & $>0.9$ & $>0.5$ & $>0.5$ & $>0.5$ \\
\hline
\end{tabular}

TABLE 3: Path coefficient and hypothesis test of the integrated model.

\begin{tabular}{|c|c|c|c|c|}
\hline Path & Standard coefficient & $T$ value & $P$ value & Results \\
\hline $\mathrm{H} 1: \mathrm{SDL} \rightarrow \mathrm{TDS}$ value & 0.132 & 0.615 & $>0.05$ & Nonsupport \\
\hline $\mathrm{H} 2: \mathrm{SDL} \rightarrow \mathrm{TDS}$ participation & 0.684 & 5.968 & $<0.001$ & Support \\
\hline $\mathrm{H} 3: \mathrm{SDL} \rightarrow \mathrm{RE}$ & 0.236 & 4.712 & $<0.001$ & Support \\
\hline $\mathrm{H} 4: \mathrm{SDL} \rightarrow \mathrm{VCC}$ & 0.271 & 4.891 & $<0.001$ & Support \\
\hline H5: TDS participation $\rightarrow$ TDS value & 0.035 & 0.698 & $>0.05$ & Nonsupport \\
\hline H6: TDS participation $\rightarrow \mathrm{RE}$ & 0.765 & 6.537 & $<0.001$ & Support \\
\hline H7: TDS participation $\rightarrow$ VCC & 0.198 & 3.526 & $<0.001$ & Support \\
\hline H8: $\mathrm{RE} \rightarrow$ TDS value & 0.023 & 1.684 & $>0.05$ & Nonsupport \\
\hline $\mathrm{H} 9: \mathrm{RE} \rightarrow \mathrm{VCC}$ & 0.798 & 14.358 & $<0.001$ & Support \\
\hline H10: VCC $\rightarrow$ TDS value & 0.912 & 32.145 & $<0.001$ & Support \\
\hline
\end{tabular}


TABLE 4: Fitting results of the subdimensional model.

\begin{tabular}{|c|c|c|c|c|c|c|c|c|}
\hline Items & $\chi^{2} / d f$ & RMSEA & IFI & CFI & TLI & PGFI & PNFI & PCFI \\
\hline Index value & 4.798 & 0.066 & 0.928 & 0.919 & 0.916 & 0.769 & 0.851 & 0.859 \\
\hline Measuring standard & $<5$ (large sample) & $<0.08$ & $>0.9$ & $>0.9$ & $>0.9$ & $>0.5$ & $>0.5$ & $>0.5$ \\
\hline
\end{tabular}

TABle 5: Path coefficient and hypothesis test of the subdimensional model.

\begin{tabular}{|c|c|c|c|c|}
\hline Path & Standard coefficient & $T$ value & $P$ value & Results \\
\hline H4a: SDL $\rightarrow$ VCC-IS & 0.668 & 5.685 & $<0.001$ & Support \\
\hline H4b: SDL $\rightarrow$ VCC-RB & 0.784 & 5.923 & $<0.001$ & Support \\
\hline H4c: SDL $\rightarrow$ VCC-ISD & 0.694 & 5.742 & $<0.001$ & Support \\
\hline H7a: TDS participation $\rightarrow$ VCC-IS & 0.587 & 5.821 & $<0.001$ & Support \\
\hline H7b: TDS participation $\rightarrow$ VCC-RB & 0.854 & 14.251 & $<0.001$ & Support \\
\hline H7c: TDS participation $\rightarrow$ VCC-ISD & 0.765 & 6.537 & $<0.001$ & Support \\
\hline H9a: RE $\rightarrow$ VCC-IS & 0.918 & 13.526 & $<0.001$ & Support \\
\hline H9b: RE $\rightarrow$ VCC-RB & 0.823 & 15.684 & $<0.001$ & Support \\
\hline H9c: RE $\rightarrow$ VCC-ISD & 0.798 & 14.354 & $<0.001$ & Support \\
\hline H10a: VCC-IS $\rightarrow$ TDS value & 0.453 & 4.876 & $<0.001$ & Support \\
\hline H10b: VCC-RB $\rightarrow$ TDS value & 0.378 & 4.325 & $<0.001$ & Support \\
\hline H10c: VCC-ISD $\rightarrow$ TDS value & 0.402 & 5.134 & $<0.001$ & Support \\
\hline
\end{tabular}

4.3.2. Structural Equation Analysis of the Subdimensional Model. AMOS22 was used to test the role of the VCC subdimension among SDL, TDS participation, RE, and TDS value. The corresponding fitting indexes and their values are shown in Table 4.

The fitting indexes all met the requirements. The path coefficients and hypothesis test in the structural equation of the subdimensional model are shown in Table 5.

Table 5 shows that SDL, TDS participation, and RE have significant effects on IS, RB, and ISD. At the same time, IS, RB, and ISD have significant influences on TDS value. Therefore, hypotheses $\mathrm{H} 4 \mathrm{a} \sim \mathrm{H} 4 \mathrm{c}$, hypotheses $\mathrm{H} 7 \mathrm{a} \sim \mathrm{H} 7 \mathrm{c}$, hypotheses $\mathrm{H} 9 \mathrm{a} \sim \mathrm{H} 9 \mathrm{c}$, and hypotheses $\mathrm{H} 10 \mathrm{a} \sim \mathrm{H} 10 \mathrm{c}$ are valid.

In conclusion, SDL, TDS participation, and RE do not directly affect TDS value but indirectly through VCC and its three subdimensions.

4.3.3. Test of Mediating Effect. In this part, the method proposed by Baron, Zhonglin Wen, and other scholars is adopted. And Mplus8.0 is used to test the mediating effect, in which SDL is $\mathrm{X} 1$, TDS participation is $\mathrm{X} 2, \mathrm{RE}$ is $\mathrm{X} 3$, VCC is M, IS is M1, RB is M2, ISD is M3, and TDS value is Y. The results are shown in Table 6.

As can be seen in Table 6, the model has a good fitting degree. According to the parameter estimates, the secondorder latent variable VCC and its three first-order latent variables, namely, IS, RB, and ISD, all have significant mediating effects on SDL, TDS participation, RE, and TDS value. Therefore, the above hypotheses are valid and VCC has a mediating effect on TDS participation in service innovation of the freight transport platform.

\section{Conclusions and Management Implications}

5.1. Conclusions and Discussions. This research puts forward a theoretical framework about the relationships among SDL, TDS participation, RE, platform VCC, and TDS value. Taking platform VCC as the mediating variable, 10 hypotheses are proposed to explain the influence mechanism of value cocreation of the network freight transport platform from the perspective of TDS participation. Through empirical analysis of the questionnaire survey, the research conclusions are as follows:

(1) SDL does not directly affect TDS value, but indirectly through VCC. Structural equation model analysis shows that $\mathrm{H} 4$ and $\mathrm{H} 10$ pass the significance test, but $\mathrm{H} 1$ does not pass the significance test. On the one hand, SDL provides the conceptual guidance for TDS participation in VCC. On the other hand, VCC provides strong support for the innovation development of transport enterprises in the IoTbased environment

(2) SDL affects not only VCC directly but also indirectly through TDS participation and RE. First, the concept of SDL unifies the value cocreation subject's understanding of the importance of VCC. The main body of the value network, such as customers, suppliers, and distributors, should take the platform provider as the core and jointly build and improve the platform ecological system, so as to achieve better value cocreation. Second, TDS participation promotes value creation. SDL emphasizes that customers are the participants of value cocreation and customer 
TABLE 6: Results of the mediating effect test.

\begin{tabular}{|c|c|c|c|c|c|c|}
\hline \multirow{2}{*}{ Path } & \multirow{2}{*}{ Estimated coefficient } & \multirow{2}{*}{ Standard deviation } & \multicolumn{2}{|c|}{ 95\% confidence interval } & \multirow{2}{*}{$P$} & \multirow{2}{*}{ Test of goodness for fit } \\
\hline & & & Lower limit & Upper limit & & \\
\hline $\mathrm{X} 1 \rightarrow \mathrm{M} \rightarrow \mathrm{Y}$ & 0.987 & 0.061 & 0.654 & 0.821 & $\leq 0.001$ & $\begin{array}{c}\mathrm{CMIN} / \mathrm{DF}=1.342, \mathrm{CFI}=0.989 \\
\mathrm{TLI}=0.987, \mathrm{RMSEA}=0.021\end{array}$ \\
\hline $\mathrm{X} 2 \rightarrow \mathrm{M} \rightarrow \mathrm{Y}$ & 0.921 & 0.094 & 0.821 & 1.084 & $\leq 0.001$ & $\begin{array}{c}\mathrm{CMIN} / \mathrm{DF}=1.627, \mathrm{CFI}=0.977 \\
\mathrm{TLI}=0.968, \mathrm{RMSEA}=0.026\end{array}$ \\
\hline $\mathrm{X} 3 \rightarrow \mathrm{M} \rightarrow \mathrm{Y}$ & 0.961 & 0.201 & 0.801 & 1.062 & $\leq 0.001$ & $\begin{array}{c}\mathrm{CMIN} / \mathrm{DF}=1.378, \mathrm{CFI}=0.984 \\
\mathrm{TLI}=0.988, \mathrm{RMSEA}=0.022\end{array}$ \\
\hline $\mathrm{X} 1 \rightarrow \mathrm{M} 1 \rightarrow \mathrm{Y}$ & 0.358 & 0.115 & 0.203 & 0.649 & 0.002 & \multirow{3}{*}{$\begin{array}{c}\mathrm{CMIN} / \mathrm{DF}=2.849, \mathrm{CFI}=0.948 \\
\mathrm{TLI}=0.931, \mathrm{RMSEA}=0.047\end{array}$} \\
\hline $\mathrm{X} 1 \rightarrow \mathrm{M} 2 \rightarrow \mathrm{Y}$ & 0.534 & 0.172 & 0.234 & 0.937 & 0.002 & \\
\hline $\mathrm{X} 1 \rightarrow \mathrm{M} 3 \rightarrow \mathrm{Y}$ & 0.512 & 0.124 & 0.365 & 0.798 & $\leq 0.001$ & \\
\hline $\mathrm{X} 2 \rightarrow \mathrm{M} 1 \rightarrow \mathrm{Y}$ & 0.301 & 0.101 & 0.162 & 0.491 & 0.002 & \multirow{3}{*}{$\begin{array}{c}\mathrm{CMIN} / \mathrm{DF}=1.957, \mathrm{CFI}=0.952 \\
\mathrm{TLI}=0.953, \mathrm{RMSEA}=0.033\end{array}$} \\
\hline $\mathrm{X} 2 \rightarrow \mathrm{M} 2 \rightarrow \mathrm{Y}$ & 0.412 & 0.126 & 0.198 & 0.612 & $\leq 0.001$ & \\
\hline $\mathrm{X} 2 \rightarrow \mathrm{M} 3 \rightarrow \mathrm{Y}$ & 0.453 & 0.135 & 0.261 & 0.698 & $\leq 0.001$ & \\
\hline $\mathrm{X} 3 \rightarrow \mathrm{M} 1 \rightarrow \mathrm{Y}$ & 0.247 & 0.171 & 0.047 & 0.568 & 0.016 & \multirow{3}{*}{$\begin{array}{c}\mathrm{CMIN} / \mathrm{DF}=1.491, \mathrm{CFI}=0.978 \\
\mathrm{TLI}=0.981, \mathrm{RMSEA}=0.024\end{array}$} \\
\hline $\mathrm{X} 3 \rightarrow \mathrm{M} 2 \rightarrow \mathrm{Y}$ & 0.384 & 0.164 & 0.098 & 0.931 & 0.022 & \\
\hline $\mathrm{X} 3 \rightarrow \mathrm{M} 3 \rightarrow \mathrm{Y}$ & 0.462 & 0.142 & 0.453 & 0.729 & $\leq 0.001$ & \\
\hline
\end{tabular}

participation accelerates the information flow between customers, platform enterprises, and suppliers and greatly improves the response speed and flexibility of the platform. Third, RE promotes VCC.Participants interact through the network platform and create value together

(3) TDS participation does not directly affect TDS value, but indirectly through VCC. On the one hand, TDS participation can continuously improve the function of the platform, realize IS and ISD, and improve the response speed and innovation ability of the platform, so that the platform can better support the main body of VCC to realize value creation. On the other hand, TDS participation is conducive to information communication and knowledge sharing among demanders, between demanders and suppliers and between suppliers on the platform, so as to realize multiparty resource integration and complementarity and promote the performance of the logistics service supply chain

(4) TDS participation affects not only VCC directly but also indirectly through ER. TDS participation has a direct impact on the platform capability, including the platform's value chain integration, organizational core, and technological innovation capabilities. At the same time, TDS participation also directly affects $\mathrm{RE}$ and indirectly affects VCC through RE. On the one hand, demanders provide their demands and suggestions to suppliers through the platform, which helps suppliers integrate the resources of partners on the value chain, innovate, and develop products and services to meet the needs of TDS. On the other hand, TDS participation indirectly affects VCC through RE.
TDS participation improves the RE between demanders and suppliers, and RE indirectly promotes the realization of resource complementarity among various subjects and promotes the improvement of value chain integration ability

(5) RE does not directly affect TDS value, but indirectly through VCC. First, RE promotes the cooperation between VCC subjects. Second, RE improves the core competence of the organization. Each subject realizes the complementarity and integration of knowledge, technology, and resources in the network embedding, and the injection of heterogeneous resources can promote the improvement of enterprise core competence. Third, RE promotes technological innovation and enhances technological innovation ability. Therefore, RE influences TDS value by promoting VCC

(6) Mediating role of VCC. The empirical analysis results show that the overall VCC plays a mediating role in the relationships between SDL and TDS value, TDS participation and TDS value, RE, and TDS value. At the same time, IS, RB, and ISD also play a mediating role in the relationship between SDL, TDS participation, RE, and TDS value

5.2. Management Implications. The results show that the key point of the transportation enterprise reform is the VCC of TDS participation in the network freight transport platform. In order to improve TDS satisfaction and loyalty, VCC needs to play an intermediary role and the deepening of VCC needs to be jointly promoted through the innovation of the SDL concept, the guidance of TDS participation, and the strengthening of the network relationship. 
(1) Establish symbiotic organizations and build the platform ecological system. First, the diversified and personalized TDS needs make demanders become the initiator of demand and the participant of value creation. The $\mathrm{C} 2 \mathrm{~B}$ model is on the rise, while the traditional B2C model is facing severe challenges. Second, as a provider of products and services, a freight transport enterprise cannot win in the competition only by its internal resources and strength and it is even more difficult to achieve new growth. Therefore, it is necessary for the freight transport enterprise to build a value network based on TDS participation in value creation, regard the members of the value network as a community of destiny, and build a symbiotic organization. Thirdly, in order to realize VCC, symbiotic organizations need the support of the platform, and the VCC platform needs to be jointly created by symbiotic organizations and entities constantly interact

(2) It is pointed out that TDS value is the core of enterprise management and the focus of the common concern of all stakeholders. Peter Drucker said that "the purpose of business is to create customers." Therefore, VCC activities start from the needs and preferences of customers. Secondly, choose partners or suppliers with corresponding resources or capabilities. Third, the use of the corresponding technology and resources to achieve product development and service provision. Finally, the product or service is delivered to the TDS through the distributor close to the TDS or the TDS himself

(3) Guide TDS to participate and improve the platform capability. Enterprises should build a sustainable competitive advantage, establish a demanderoriented culture and machine, and provide support for TDS participation. One is to establish the "TDScentered" service concept and create a cultural atmosphere of TDS participation. Second is to establish the incentive mechanism and operation process of TDS participation. The third is to provide tools and platforms for TDS participation

(4) Optimize network structure and enhance platform capability. First, build a culture of the shared vision, values, and identity to achieve relationship embedding. Secondly, optimize the network to expand the scale of the network and encourage more participants to participate, to achieve more heterogeneous resource integration. The frequency of contact and interaction among partners such as TDS, platform providers, and suppliers can improve the relationship quality among VCC subjects and promote the improvement of platform capability through good relationship embedding

5.3. Research Limitations and Prospects. Although this research has analyzed and studied the influence mechanism of VCC of the network freight transport platform from the aspects of SDL, TDS participation, RE, and VCC, there are still some shortcomings. It is mainly reflected in the following aspects: first, only the overall analysis of TDS participation is carried out and the specific dimensions such as the willingness, motivation, and behavior of TDS to participate in VCC of freight transport platform are not analyzed and displayed. Future research can strengthen this part of the content. Second, there is no in-depth analysis and research on the influence of various dimensions of RE on VCC and TDS value. Future research can increase the influence analysis of trust, communication, and commitment on VCC and TDS value. Third, the scope of the investigation is small. Only one industry is taken as an example. Future research can expand the scope of investigation to multiple industries and enterprises and test the theoretical model with multicase analysis. Fourth, the environmental factor is not considered in this study and subsequent studies should focus on the moderating effect of environmental dynamics.

\section{Data Availability}

The data used to support the findings of this study are available from the corresponding author upon request.

\section{Conflicts of Interest}

The authors declare no conflict of interest.

\section{Authors' Contributions}

Conceptualization was done by P.B. and Q.L. Data curation was done by P.B. and Q.L. Funding acquisition was done by Q.L. and B.C. Investigation was one P.B. and Y.J. Methodology was done by P.B. and B.C. Project administration was done by Q.L. and B.C. Resources were acquired by Q.L. and L.Z. Supervision was done by Q.W. Validation was done by Q.W. Visualization was done by L.Z. and Y.J. Writing and original draft preparation were done by P.B. and Q.L. Writing, review, and editing were done by Q.L. and L.Z.

\section{Acknowledgments}

This research was supported by the National Social Science Foundation of China (no. 19CGL004), Shaanxi Education Department Foundation (no. 19JZ011), Shaanxi Social Science Foundation (nos. 2019D013 and 2020D028), research program funded by Shaanxi Provincial Philosophy and Social Sciences Major Theoretical and Practical Issues (no. 2021ND0444), and Central Universities Fundamental Research Foundation for Chang'an University (nos. 300102231603, 300102231615, and 300102341677).

\section{References}

[1] Y. W. Lee, H.-C. Moon, and W. Yin, "Innovation process in the business ecosystem: the four cooperations practices in the media platform," Business Process Management Journal, vol. 26, no. 4, pp. 943-971, 2020.

[2] Y. K. Lew, J. Kim, and Z. Khan, "Technological adaptation to a platform and dependence: value co-creation through 
partnerships," Asian Journal of Technology Innovation, vol. 27, no. 1, pp. 71-89, 2019.

[3] B. Peng, Y. Wang, S. Zahid, G. Wei, and E. Elahi, "Platform ecological circle for cold chain logistics enterprises: the value co-creation analysis," Industrial Management \& Data Systems, vol. 120, no. 4, pp. 675-691, 2020.

[4] K. D. Bahn†, K. L. Granzin, and M. Tokman, "End-User contribution to logistics value co-creation: a series of exploratory studies," Journal of Marketing Channels, vol. 22, no. 1, pp. 326, 2015.

[5] K. A. Vakeel, E. C. Malthouse, and A. Yang, "Impact of network effects on service provider performance in digital business platforms," Journal of Service Management, vol. aheadof-print, no. ahead-of-print, 2020.

[6] L. V. Ngo and A. O'Cass, "Innovation and business success: the mediating role of customer participation," Journal of Business Research, vol. 66, no. 8, pp. 1134-1142, 2013.

[7] Y. Fernando and C. Chukai, "Value co-creation, goods and service tax (GST) impacts on sustainable logistic performance," Research in Transportation Business \& Management, vol. 28, pp. 92-102, 2018.

[8] S.-T. D. Yuan, S. Y. Chou, W. C. Yang, C. A. Wu, and C. T. Huang, "Customer engagement within multiple new media and broader business ecosystem - a holistic perspective," Kybernetes, vol. 46, no. 6, pp. 1000-1020, 2017.

[9] M. L. Santos-Vijande, J. Á. López-Sánchez, and P. Pascual-Fernández, "Co-creation with clients of hotel services: the moderating role of top management support," Current Issues in Tourism, vol. 21, no. 3, pp. 301-327, 2018.

[10] V. Marino and L. Lo Presti, "Engagement, satisfaction and customer behavior-based CRM performance," Journal of Service Theory and Practice, vol. 28, no. 5, pp. 682-707, 2018.

[11] J. Carlson, M. Rahman, R. Voola, and N. de Vries, "Customer engagement behaviours in social media: capturing innovation opportunities," Journal of Services Marketing, vol. 32, no. 1, pp. 83-94, 2018.

[12] C.-C. Chu, Y. F. Cheng, F. S. Tsai, S. B. Tsai, and K. H. Lu, "Open innovation in crowdfunding context: diversity, knowledge, and networks," Sustainability, vol. 11, no. 1, p. 180, 2019.

[13] N. Hasan and A. A. Rahman, "Ranking the factors that impact customers online participation in value co-creation in service sector using analytic hierarchy process," International Journal of Information Systems in the Service Sector, vol. 9, no. 1, pp. 37-53, 2017.

[14] C. Drummond, H. McGrath, and T. O'Toole, "The impact of social media on resource mobilisation in entrepreneurial firms," Industrial Marketing Management, vol. 70, pp. 68-89, 2018.

[15] J. Frempong, J. Chai, E. M. Ampaw, D. O. Amofah, and K. W. Ansong, "The relationship among customer operant resources, online value co-creation and electronic-word-of-mouth in solid waste management marketing," Journal of Cleaner Production, vol. 248, p. 119228, 2020.

[16] T. Hurni, T. L. Huber, J. Dibbern, and O. Krancher, "Complementor dedication in platform ecosystems: rule adequacy and the moderating role of flexible and benevolent practices," European Journal of Information Systems, pp. 1-24, 2020.

[17] M. J. J. Lin and C. H. Huang, "The impact of customer participation on NPD performance: the mediating role of interorganisation relationship," Journal of Business \& Industrial Marketing, vol. 28, no. 1, pp. 3-15, 2013.
[18] V. Ramaswamy and K. Ozcan, "What is co-creation? An interactional creation framework and its implications for value creation,” Journal of Business Research, vol. 84, pp. 196-205, 2018.

[19] J. Frempong, J. Chai, and E. Ampaw, "Effects of waste management customer online value co-creation on sanitation attitude and advocacy: a customer-enterprise dyadic perspective," Sustainability, vol. 10, no. 7, p. 2557, 2018.

[20] M. Sartas, P. van Asten, M. Schut et al., "Factors influencing participation dynamics in research for development interventions with multi-stakeholder platforms: a metric approach to studying stakeholder participation," PLoS One, vol. 14, no. 11, article e0223044, 2019.

[21] H. Widjojo, A. Fontana, G. Gayatri, and A. W. Soehadi, "Value co-creation for marketing innovation: comparative study in the Sme community," International Journal of Innovation Management, vol. 24, no. 3, p. 2050030, 2020.

[22] J. Yu, Y. Wen, J. Jin, and Y. Zhang, "Towards a servicedominant platform for public value co-creation in a smart city: evidence from two metropolitan cities in China," Technological Forecasting and Social Change, vol. 142, pp. 168-182, 2019.

[23] H. Pan, "Online community value co-creation," Online Information Review, vol. 44, no. 3, pp. 645-669, 2020.

[24] A. Abdelgawad and K. Yelamarthi, "Internet of Things (IoT) platform for structure health monitoring," Wireless Communications and Mobile Computing, vol. 2017, 10 pages, 2017.

[25] C. Wang and C.-H. Chen, "An E-commerce economic dynamic data evaluation model based on multiuser demand constraints," Wireless Communications and Mobile Computing, vol. 2021, 9 pages, 2021.

[26] S. Wu, H. Kou, C. Lv, W. Huang, L. Qi, and H. Wang, "Service recommendation with high accuracy and diversity," Wireless Communications and Mobile Computing, vol. 2020, 10 pages, 2020.

[27] G. Shen, W. Wang, Q. Mu, Y. Pu, Y. Qin, and M. Yu, "Datadriven cybersecurity knowledge graph construction for industrial control system security," Wireless Communications and Mobile Computing, vol. 2020, 13 pages, 2020.

[28] J. A. Fehrer, H. Woratschek, and R. J. Brodie, "A systemic logic for platform business models," Journal of Service Management, vol. 29, no. 4, pp. 546-568, 2018.

[29] T. G. Pittz and T. Adler, "An exemplar of open strategy: decision-making within multi-sector collaborations," Management Decision, vol. 54, no. 7, pp. 1595-1614, 2016.

[30] N. Rubio, N. Villaseñor, and M. J. Yagüe, "Sustainable cocreation behavior in a virtual community: antecedents and moderating effect of participant's perception of own expertise," Sustainability, vol. 12, no. 19, p. 8151, 2020.

[31] B. Sarmah, S. Kamboj, and J. Kandampully, "Social media and co-creative service innovation: an empirical study," Online Information Review, vol. 42, no. 7, pp. 1146-1179, 2018.

[32] S. P. Singaraju, Q. A. Nguyen, O. Niininen, and G. Sullivan-Mort, "Social media and value co-creation in multi-stakeholder systems: a resource integration approach," Industrial Marketing Management, vol. 54, pp. 44-55, 2016.

[33] R. R. Sinkovics, O. Kuivalainen, and A. S. Roath, "Value cocreation in an outsourcing arrangement between manufacturers and third party logistics providers: resource commitment, innovation and collaboration," Journal of Business \& Industrial Marketing, vol. 33, no. 4, pp. 563-573, 2018.

[34] L. T. Tuan, "Under entrepreneurial orientation, how does logistics performance activate customer value co-creation 
behavior?," The International Journal of Logistics Management, vol. 28, no. 2, pp. 600-633, 2017.

[35] M. B. Tudose, G. Agafitei, and S. Avasilcai, "New research direction on performance and co-creation: a literature review," IOP Conference Series: Materials Science and Engineering, vol. 898, 2020.

[36] B. Xu, H. Zheng, Y. Xu, and T. Wang, "Configurational paths to sponsor satisfaction in crowdfunding," Journal of Business Research, vol. 69, no. 2, pp. 915-927, 2016.

[37] S. Ahmad, A. Badwelan, A. M. Ghaleb et al., "Analyzing critical failures in a production process: is industrial IoT the solution?,"Wireless Communications and Mobile Computing, vol. 2018, 12 pages, 2018.

[38] A. Biørn-Hansen, T. M. Grønli, G. Ghinea, and S. Alouneh, "An empirical study of cross-platform mobile development in industry," Wireless Communications and Mobile Computing, vol. 2019, 12 pages, 2019.

[39] A. Busson and I. Lahsen-Cherif, "Impact of resource blocks allocation strategies on downlink interference and SIR distributions in LTE networks: a stochastic geometry approach," Wireless Communications and Mobile Computing, vol. 2018, 15 pages, 2018.

[40] P. Chamoso, A. González-Briones, S. Rodríguez, and J. M. Corchado, "Tendencies of technologies and platforms in smart cities: a state-of-the-art review," Wireless Communications and Mobile Computing, vol. 2018, 17 pages, 2018.

[41] S. Chen and H. Cheng, "Analysis of customization strategy for E-commerce operation based on big data," Wireless Communications and Mobile Computing, vol. 2021, 11 pages, 2021.

[42] S. Delle Monache, L. Comanducci, M. Buccoli et al., "A presence- and performance-driven framework to investigate interactive networked music learning scenarios," Wireless Communications and Mobile Computing, vol. 2019, 20 pages, 2019.

[43] D. Deng, C. Li, L. Fan, X. Liu, and F. Zhou, "Impact of antenna selection on physical-layer security of NOMA networks," Wireless Communications and Mobile Computing, vol. 2018, 11 pages, 2018.

[44] J. J. Escudero-Garzás and C. Bousoño-Calzón, “An analysis of the network selection problem for heterogeneous environments with user-operator joint satisfaction and multi-RAT transmission," Wireless Communications and Mobile Computing, vol. 2017, 13 pages, 2017.

[45] M. Pasha and S. M. W. Shah, "Framework for E-health systems in IoT-based environments," Wireless Communications and Mobile Computing, vol. 2018, 11 pages, 2018.

[46] T. Leclercq, I. Poncin, and W. Hammedi, “The engagement process during value co-creation: gamification in new product-development platforms," International Journal of Electronic Commerce, vol. 21, no. 4, pp. 454-488, 2017.

[47] M. Imran, H. A. Khattak, D. Millard, T. Tiropanis, T. Bashir, and G. Ahmed, "Calculating trust using multiple heterogeneous social networks," Wireless Communications and Mobile Computing, vol. 2020, 14 pages, 2020.

[48] H. Kou, F. Wang, C. Lv et al., "Trust-based missing link prediction in signed social networks with privacy preservation," Wireless Communications and Mobile Computing, vol. 2020, 10 pages, 2020.

[49] A. Lakas, M. E. A. Fekair, A. Korichi, and N. Lagraa, "A multiconstrained QoS-compliant routing scheme for highway- based vehicular networks," Wireless Communications and Mobile Computing, vol. 2019, 18 pages, 2019.

[50] W. Li, L. Yang, Z. Wen, J. Chen, and X. Wu, "On the optimization strategy of EV charging station localization and charging piles density," Wireless Communications and Mobile Computing, vol. 2021, 13 pages, 2021.

[51] X. Li, X. Jin, Q. Wang, M. Cao, and X. Chen, "SCCAF: a secure and compliant continuous assessment framework in cloudbased IoT context," Wireless Communications and Mobile Computing, vol. 2018, 18 pages, 2018.

[52] P. Bai, Q. Wu, Q. Li, C. Xue, and L. Zhang, "Mediating effect of organizational learning capacity on the relationship between relational embeddedness and innovation performance in freight logistics service," Complexity, vol. 2021, 18 pages, 2021. 